\title{
Pre-Service Teachers' Evaluation of Teaching and Learning of Core Courses in Regular and Distance Education Programmes in Ghanaian Colleges of Education
}

\author{
Millicent Narh-Kert \\ Department of Teacher Education, University of Ghana, Legon, Ghana \\ Email: mnarh-kert@ug.edu.gh
}

How to cite this paper: Narh-Kert, M. (2021). Pre-Service Teachers' Evaluation of Teaching and Learning of Core Courses in Regular and Distance Education Programmes in Ghanaian Colleges of Education. Open Journal of Social Sciences, 9, 499-509. https://doi.org/10.4236/jss.2021.99036

Received: August 25, 2021

Accepted: September 20, 2021

Published: September 23, 2021

Copyright $\odot 2021$ by author(s) and Scientific Research Publishing Inc. This work is licensed under the Creative Commons Attribution International License (CC BY 4.0).

http://creativecommons.org/licenses/by/4.0/ (c) (i) Open Access

\begin{abstract}
Almost all pre-service teachers from Colleges of Education in Ghana, whether from the regular or distance mode, teach in the basic schools. This research employed survey to examine pre-service teachers' evaluation of teaching (ET) on teaching and learning in the regular and distance modes of teacher education in Ghana. The analytical cross-sectional survey design was adopted for the study. Four hundred and fifty-five (455) pre-service teachers of Accra College of Education and the College of Distance Education at Papafio Hills, both of University of Cape Coast were used as the sample for the survey. Questionnaire of Cronbach's alpha coefficient ( $\alpha$ ) of 0.81 was used to solicit views regarding students' evaluation of teaching and learning. Frequency and percentages were used to describe the data. They have the belief that tutors are competent in subject matter knowledge, pedagogy and assessment. Empirically, tutors' knowledge of subject matter was rated 'good' by majority of distance $(89.57 \%)$ and regular (51.17\%) students. Organization of lessons by the college tutors was also judged as good by majority of the distance $(73.07 \%)$ and regular (61.67\%) students. Teacher assessment by college tutors was rated "good" and constructive by majority (66.0\%) of the distance students, and a few regular students $(36.8 \%)$. Similarly, pre-service teachers in the two colleges have positive self-efficacy in learning. Evidence from the study shows that, majority of the male (64.56\%) and female (53.25\%) students in the distance mode as well as female students in the regular mode (52.25\%) did not find it stressful using mathematics and science textbooks to work on homework, except a few male students $(48.41 \%)$ in the regular mode. Pre-service teachers have the belief that College of Education tutors in Ghana are competent in subject matter knowledge and pedagogy to teach in both regular and
\end{abstract}


distance education programmes. Pre-service teachers in Ghanaian College of Education have self-efficacy in learning core courses in regular and distance education programmes. This study concludes that distance education programmes are equally effective and efficient means of education and training of pre-service teachers in Ghana just as the regular or traditional mode of teacher education and training. It is therefore recommended that, policy makers including the Ministry of Education and the National Council on Tertiary Education in liaison with Ghanaian universities should give similar attention to distance education just as it is done to the regular pre-service teacher education programmes in Ghanaian colleges of education.

\section{Keywords}

Pre-Service Teacher, Distance Education, Regular Education, Self-Efficacy, Teacher Competency

\section{Introduction}

In Ghana, teacher training and education have gone through a lot of reforms in a bid to revamp the sector in terms of producing competent and effective teachers. Effective teaching requires an understanding of the underlying meaning of concepts and procedures, as well as justifications for the ideas and procedures presented and the ability to make connections among topics (Ball, Sleep, Boerst, \& Bass, 2009; Narh-Kert, 2020; Narh-Kert \& Ampadu, 2021). Teachers for the basic school level are trained by Colleges of Education (CoEs) and the context of this study is the evaluation of teachers who teach the teachers for the basic schools in Ghana. Teachers play an essential role in quality education as noted by Cavanaugh (2001), saying: "The quality of an education system cannot exceed the quality of its teachers" (p. 16). The worth of the teacher adds more to learner success than any other variable, including class size, class composition, or background (Bailleul, Bataille, Langlois, Lanoe, \& Mazereau, 2008; Ball, Sleep, Boerst, \& Bass, 2009; Narh-Kert, Agyeman, \& Crankson, 2021; Savolainen, 2009). This study is of the view that, the evaluation will inform the participants and the readers of the results as it shapes their own teacher professional practice.

The pre-service teachers pursue Diploma in Basic Education (DBE) either via "regular education" or "distance and sandwich education" programme modes. "Distance education", or "learning at a distance", is said to share many of the common characteristics of "traditional" or "face-to-face" courses, yet it is sometimes seen as new variables in teaching and education (Crankson, Agyeman, \& Narh-Kert, 2020). With the introduction of "distance education" programme, there are expanded opportunities for both the initial training and later upgrading of teachers.

Learning occurs as much as in distance education as it does in traditional or regular education programmes. Notwithstanding, a serious argument has been 
waged as to which mode of teacher education is better. This raises different opinions about distance learning as against traditional face-to-face education. Some say that distance education is viewed as being different from other forms of education. What is actually in clash is not whether distance education is ideal, but whether it is good enough to merit a college or university degree, and whether it is better than receiving no education at all cost. Although there are many empirical studies regarding the debate on this phenomenon worldwide (Bernard, Abrami, Lou, Borokhovski, Wade, Wozney, \& Huang, 2004; Cavanaugh, 2001; Crankson, Agyeman, \& Narh-Kert, 2020; Cybinski \& Selvanathan, 2005; Deka \& McMurry, 2006; Machtmes \& Asher, 2000; Narh-Kert, Agyeman, \& Crankson, 2021; Shachar \& Neumann, 2003), there is very little study about it in Ghana. It is against this backdrop that this study looks at pre-service teachers' evaluation of teaching (ET) on teaching and learning in the regular and distance modes of teacher education.

Empirically, previous studies cited above have concluded that "distance education" courses are as efficient as the traditional "face-to-face courses". These studies reported that students' attainment in distance education can be regarded as good as that of students in the "face-to-face" courses. Some of the studies have also affirmed that students' attainment in distance education settings will have a more positive drift than in the traditional face-to-face settings in the near future (Deka \& McMurry, 2006; Ramage, 2002; Savolainen, 2009; Schoenfeld-Tacher, McConnell, \& Graham, 2001). It has also been proven that distance education students perform well when compared to on-campus face-to face students, either showing no significant differences or slight increase in class grades (Narh-Kert, 2020; Narh-Kert \& Ampadu, 2021; Tucker, 2000; Zhao, Lei, Yan, \& Tan, 2004). Some researchers (Cybinski \& Selvanathan, 2005; Narh-Kert \& Ampadu, 2020) found a statistically significant learning difference between distance education learners and traditional face-to-face learners in the following variables: reading comprehension with $(p<0.04)$ and academic success with $(p<0.03)$. Researchers (Ramage, 2002; Zhao, Lei, Yan, \& Tan, 2004) investigated students' performance in an introductory statistic in two (2) learning modes (traditional and flexible learning environments). They observed that there were no differences in performance outcomes between the two learning modes with $p$-value of 0.25 and 0.14 for traditional and flexible learning environments respectively. Researchers (Schoenfeld-Tacher, McConnell, \& Graham, 2001; Savolainen, 2009) when they compared students' final scores in "distance education" with those in traditional classes, resulted in an overall effect size of 0.37 . They concluded that the final academic performance grades of students enrolled in distance education programs are higher than those enrolled in traditional face-to face programs. Likewise, researchers (Machtmes \& Asher, 2000; Cavanaugh, 2001) reviewed literature of empirical studies between 1985 and 2002, which focused on investigating the effectiveness of distance education compared with its traditional classroom-based counterparts. They found that there was a small but significant effect favoring distance education conditions. From the empirical literature reviewed. It is ex- 
pedient to also look at the classroom evaluation of both the distance and the regular students of colleges of education Ghana, hence this study.

\section{Materials and Methods}

The analytical cross-sectional survey design was adopted for the study. The target population for this study was all Diploma in Basic Education (DBE) students who were pre-service teachers of Accra College of Education and the College of Distance Education at Papafio Hills, both of University of Cape Coast. A total of 455 students consisting of 299 regular (full-time) and 156 distance education students were selected through practical census, purposive and convenient sampling techniques for the study. This comprised 188 male and 111 female students in the regular mode as well as 79 male and 77 female students in the distance mode. In all, 267 male and 188 female students took part in the survey. Only pre-service teachers offering general courses were purposively sampled. Only second year group of colleges of education students were conveniently sampled for the study. Questionnaire with Cronbach's alpha reliability coefficient ( $\alpha$ ) of 0.81 was used to gather data from the 455 students. Thus, quantitative data were analyzed descriptively using frequency and percentage.

\section{Results}

Students' Evaluation on Teaching (SET) of tutors' knowledge in subject matter and tutors ability to organize instruction (lesson) for both regular and distance modes in the Diploma in Basic Education (DBE) course are presented in this section.

In Table 1, the students rated tutors' knowledge of subject matter in teaching both DBE courses for both regular and distance learning modes as "good" and excellent. For tutors' knowledge of subject matter in teaching, a few regular students rated it as "good" (29.1\%) and "excellent" (23.07\%). Similarly, a few distance students graded it as "good" (29.1\%) and the majority (61.54\%) rated it "excellent". Comparatively, it could be concluded that more (89.57\%) distance students than their regular mode counterparts (51.17\%) assessed tutors' knowledge of subject matter as above average. On whether tutors need improvement

Table 1. Students' assessment of subject matter knowledge of tutors $(\mathrm{n}=455)$.

\begin{tabular}{ccc}
\hline \multirow{2}{*}{ Rating Scale } & \multicolumn{2}{c}{ Learning Mode } \\
\cline { 2 - 3 } Poor & Regular & Distance \\
\hline Needs improvement & $2(0.67)$ & $1(0.64)$ \\
Satisfactory & $43(14.38)$ & $1(0.64)$ \\
Good & $98(32.78)$ & $14(8.97)$ \\
Excellent & $87(29.10)$ & $44(28.21)$ \\
Total & $69(23.07)$ & $96(61.54)$ \\
\end{tabular}


in subject matter knowledge in teaching DBE courses for both regular and distance learning modes, only a few regular students (14.38\%) and distance students $(0.64 \%)$ answered in the affirmative.

In Table 2, the students rated tutors' organization of lessons in teaching both regular and distance learning modes as "good" and "excellent". A few regular students ranked it as "good" (44.15\%) and "excellent" (17.47\%), whereas a few distance students rated it as "good" (45.51\%) and "excellent" (27.56\%). It could be inferred that more $(73.07 \%)$ distance students than their regular mode counterparts (61.67\%) assessed tutors' organization of lessons as most satisfactory. Notwithstanding, a few regular students (17.73\%) and distance students (10.25\%) answered in the affirmative on the need for tutors to improve on organization of lessons.

In Table 3, only few regularly students rated tutors as "good" (18.1\%) and "excellent" (18.7\%) in providing fair and constructive feedback on academic performance. On the other hand, a few distance students assessed tutors as "good" (41.0\%) and "excellent" (25.0\%) in providing objective feedback on their performance. It is concluded that more distance students (66.0\%) than the regular students $(36.8 \%)$ rated tutors as providing constructive feedback on academic performance. On whether tutors need improvement in providing constructive feedback, a few regular students (17.4\%) and distance students (5.8\%) answered in the affirmative.

Table 2. Students' assessment of organisation of lessons by tutors $(\mathrm{n}=455)$.

\begin{tabular}{ccc}
\hline \multirow{2}{*}{ Rating Scale } & \multicolumn{2}{c}{ Learning Mode } \\
\cline { 2 - 3 } & Regular & Distance \\
\hline Poor & $5(1.67)$ & $1(0.64)$ \\
Needs improvement & $53(17.73)$ & $16(10.25)$ \\
Satisfactory & $69(23.08)$ & $26(8.70)$ \\
Good & $132(44.15)$ & $71(45.51)$ \\
Excellent & $40(17.47)$ & $43(27.56)$ \\
Total & $299(100)$ & $156(100)$ \\
\hline
\end{tabular}

Table 3. Students' assessment of whether tutors provide them with constructive feedback on their academic performance $(\mathrm{n}=455)$.

\begin{tabular}{ccc}
\hline \multirow{2}{*}{ Rating Scale } & \multicolumn{2}{c}{ Learning Mode } \\
\cline { 2 - 3 } & Regular & Distance \\
\hline Poor & $18(6.0)$ & $12(7.7)$ \\
Needs improvement & $52(17.4)$ & $9(5.8)$ \\
Satisfactory & $119(39.8)$ & $32(20.1)$ \\
Good & $54(18.1)$ & $64(41)$ \\
Excellent & $56(18.7)$ & $39(25)$ \\
Total & $299(100)$ & $156(100)$
\end{tabular}


Table 4 shows the perception of male and female students on whether they feel uncertain and confused when tutors teach quantitative related courses, particularly mathematics. In the basic school system in Ghana, the quantitative courses are mathematics and science. Majority of the male students in the regular mode (69.14\%) and distance mode (68.35\%) did not feel uncertain and confused when their tutors taught them quantitative related courses. Comparatively, most of the female students in the regular mode $(72.0 \%)$ and distance mode (51.95\%) held same view. This result means that both male and female students in the regular and distance education modes felt certain and positive when tutors teach quantitative related courses.

'Table 5 presents students' views on whether it is stressful to use mathematics and science textbooks to work on homework. A few male students (48.41\%) in

Table 4. Students' views on whether they feel uncertain and confused when tutors teach them quantitative related courses $(n=455)$.

\begin{tabular}{cccc}
\hline \multirow{2}{*}{ Sex } & Rating Scale & \multicolumn{2}{c}{ Learning Mode } \\
\cline { 2 - 4 } & Strongly Disagree & $31(16.49)$ & Distance \\
\hline \multirow{2}{*}{ Male } & Disagree & $99(52.65)$ & $24(30.38)$ \\
& Neutral & $50(26.60)$ & $30(37.97)$ \\
& Agree & $8(4.26)$ & $20(25.32)$ \\
& Strongly Agree & $0(0.00)$ & $2(3.80)$ \\
& Strongly Disagree & $27(24.32)$ & $10(12.99)$ \\
Female & Disagree & $53(47.75)$ & $30(38.96)$ \\
& Neutral & $28(25.23)$ & $29(37.67)$ \\
& Agree & $3(2.70)$ & $0(0.00)$ \\
& Strongly Agree & $0(0.00)$ & $8(10.39)$ \\
\hline
\end{tabular}

Table 5. Students' views on whether it is stressful to use mathematics and science textbooks to work on homework $(\mathrm{n}=455)$.

\begin{tabular}{cccc}
\hline \multirow{2}{*}{ Sex } & Rating Scale & \multicolumn{2}{c}{ Learning Mode } \\
\cline { 2 - 3 } & Strongly Disagree & $25(13.30)$ & Distance \\
\hline \multirow{2}{*}{ Male } & Disagree & $66(35.11)$ & $24(30.38)$ \\
& Neutral & $72(38.30)$ & $27(34.18)$ \\
& Agree & $23(12.23)$ & $7(8.86)$ \\
& Strongly Agree & $23(12.23)$ & $6(7.59)$ \\
Female & Strongly Disagree & $11(9.91)$ & $25(3.53)$ \\
& Disagree & $41(42.34)$ & $16(20.78)$ \\
& Neutral & $39(35.13)$ & $9(11.69)$ \\
& Agree & $20(18.02)$ & $15(19.48)$ \\
& Strongly Agree & $0(0.00)$ & $12(15.58)$ \\
\hline
\end{tabular}


the regular mode and majority (64.56\%) in the distance mode did not find it stressful using mathematics and science textbooks to work on homework. Similarly, majority of the female students in the regular mode (52.25\%) and distance mode (53.25\%) held congruent views. This result implies that majority of the students in both the regular and distance education modes had no difficulty in using mathematics and science textbooks to work on their homework.

Table 6 presents students' views on whether they prefer studying English Language in the regular and distance modes at college. A few male students (38.83\%) in the regular mode and majority $(78.48 \%)$ in the distance mode disliked studying the subject at college, but a few male students in the regular mode (31.91\%) and distance mode (19.99\%) preferred it. On the other, a few female students (43.24\%) in the regular mode and majority (67.54\%) in the distance mode disliked studying English Language at college, but a few female students in the regular mode (38.74\%) and distance mode (22.08\%) preferred it. It could be concluded from the results majority of the male and female students in the regular mode (78.48\%) and distance mode (67.54\%) did not prefer studying English Language at college. Both male and female students in the regular mode held incongruent views. It is likely that the distance students disliked studying the subject at college because they had already acquired the requisite content knowledge in the secondary school. This entry level knowledge (ELK) of students shapes their thinking, practices, attitude and interest towards a particular subject at college. This is to say that the attitude of pre-service teachers towards the studying of English Language at CoEs is nothing different from the attitude and interest of students towards the subject at the secondary level. It is also plausible that the regular students preferred and showed interest in studying it in order to acquire pedagogical knowledge or methodology of teaching it.

Table 6. Students' views on whether they prefer studying English Language in the regular and distance modes at college $(\mathrm{n}=455)$.

\begin{tabular}{cccc}
\hline \multirow{2}{*}{ Sex } & Rating Scale & \multicolumn{2}{c}{ Learning Mode } \\
\cline { 2 - 3 } & Strongly Disagree & $20(10.64)$ & Distance \\
\hline \multirow{2}{*}{ Male } & Disagree & $53(28.19)$ & $36(45.57)$ \\
& Neutral & $55(29.26)$ & $26(32.91)$ \\
& Agree & $42(22.34)$ & $1(1.27)$ \\
& Strongly Agree & $18(9.57)$ & $7(8.86)$ \\
\hline Strongly Disagree & $13(11.71)$ & $26(33.77)$ \\
Female & Disagree & $35(31.53)$ & $26(33.77)$ \\
& Neutral & $20(18.02)$ & $8(10.39)$ \\
& Agree & $20(18.02)$ & $9(11.69)$ \\
& Strongly Agree & $23(20.72)$ & $8(10.39)$
\end{tabular}




\section{Discussions}

The study found that, students had positive views on tutors' knowledge of subject matter and organization of lessons. It came to light that In the Colleges of Education surveyed, tutors' knowledge of subject matter was rated to be good by majority of both distance $(89.57 \%)$ and regular (51.17\%) students. Similarly, organization of lessons by the college tutors was judged as good by majority of the distance (73.07\%) and regular (61.67\%) students. Majority (66.0\%) of the distance students, but a few regular students $(36.8 \%)$ rated tutors as providing constructive feedback on academic performance. This is to say that, pre-service teachers have the belief that College of Education tutors in Ghana are competent in subject matter knowledge and pedagogy to teach in both regular and distance education programmes. This is to justify that teacher competency contributes to learner success. This finding echoes the views of other researchers (Bernard, Abrami, Lou, Borokhovski, Wade, Wozney, \& Huang, 2004; Cavanaugh, 2001; Crankson, Agyeman, \& Narh-Kert, 2020; Cybinski \& Selvanathan, 2005; Deka \& McMurry, 2006; Machtmes \& Asher, 2000; Narh-Kert, Agyeman, \& Crankson, 2021; Shachar \& Neumann, 2003), who pointed out that the worth of the teacher, measured in teacher repertoire in subject matter knowledge and competency, play an essential role in quality education and adds more to learner success than any other variable.

The findings of this study is also an indication that Ghanaian Colleges of Education tutors in both regular and distance education programme are as effective and efficient to teach students. In other words, distance education tutors are of worth just as the regular tutors to teach college courses. These findings are parallel to the views of several researchers who concluded that distance education courses are as effective and efficient as the traditional face-to-face courses (Allen, Bourhis, Burrell, \& Mabry, 2002; Bernard, Abrami, Lou, Borokhovski, Wade, Wozney, \& Huang, 2004; Cavanaugh, 2001; Crankson, Agyeman, \& Narh-Kert, 2020; Cybinski \& Selvanathan, 2005; Deka \& McMurry, 2006; Machtmes \& Asher, 2000; Narh-Kert, 2020; Narh-Kert, Agyeman, \& Crankson, 2021; Shachar \& Neumann, 2003), The survey found that, pre-service teachers in Ghanaian Colleges of Education have positive self-efficacy in learning core courses in regular and distance education programmes. The study indicated that most of the students in both the regular and distance education modes had no difficulty in using mathematics and science textbooks to work on their homework. Evidence gathered from the study indicated that, majority of the male (64.56\%) and female (53.25\%) students in the distance mode as well as female students in the regular mode (52.25\%) did not find it stressful using mathematics and science textbooks to work on homework, except a few male students (48.41\%) in the regular mode. The plausible reason is that the students had competent tutors who taught and provided them with constructive feedback that aid students' learning. This finding validates the views of other researchers (Allen, Bourhis, Burrell, \& Mabry, 2002; Crankson, Agyeman, \& Narh-Kert, 2020; Cybinski \& Selvanathan, 2005; 
Deka \& McMurry, 2006) who pointed out that the worth of the teacher, measured in teacher repertoire in subject matter knowledge and competency, play an essential role in quality education and adds more to learner success than any other variable.

The survey found that, majority of the male and female students in the regular mode (78.48\%) and distance mode (67.54\%) did not prefer studying English Language at college. It is likely that the distance students disliked studying the subject at college because they had already acquired the requisite content knowledge in the secondary school. This entry level knowledge (ELK) of students shapes their thinking, practices, interest and attitude towards a particular subject or course of study. This is to say that the attitude of pre-service teachers towards the studying of English Language at CoEs is nothing different from the attitude of students towards the subject at the secondary school level. It is also plausible that the regular students preferred and showed interest in studying it in order to acquire pedagogical knowledge or methodology of teaching it. This is because effective teaching requires an understanding and presentation of the underlying concepts and procedures. This finding corroborates the views of other researchers (Allen, Bourhis, Burrell, \& Mabry, 2002; Deka \& McMurry, 2006) who posited that effective teaching requires an understanding of the underlying meaning of concepts and procedures, as well as justifications for the ideas and procedures presented and the ability to make connections among.

\section{Conclusion}

This study has gone through systematic processes and therefore concludes that, distance education programmes are equally effective and efficient means of education and training of pre-service teachers in Ghana just as the regular or traditional mode of teacher education and training. This is because College of Education tutors have the repertoire of subject matter knowledge, and competency in teaching and assessment of courses. It also concluded that, pre-service teachers' attitude towards studying major (core) college courses is partly dependent on their Entry Level Knowledge (ELK) (Narh-Kert, 2020). Based on the findings of this research, it is recommended that policy makers including the Ministry of Education and the National Council on Tertiary Education in liaison with Ghanaian universities should give similar attention to distance education just as it is done to the regular pre-service teacher education programmes in Ghanaian colleges of education. The Ministry of Education should re-visit the national policy on science and mathematics education for females initiated by the Government of Ghana so as to motivate female students to develop interest in quantitative courses like mathematics and science right from the basic level.

\section{Conflicts of Interest}

The author declares no conflicts of interest regarding the publication of this paper. 


\section{References}

Allen, M., Bourhis, J., Burrell, N., \& Mabry, E. (2002). Comparing Student Satisfaction with Distance Education to Traditional Classrooms in Higher Education: A Meta-Analysis. American Journal of Distance Education, 16, 83-97. https://doi.org/10.1207/S15389286AJDE1602 3

Bailleul, P., Bataille, A., Langlois, C., Lanoe, P., \& Mazereau, P. (2008). From Disabled Pupils' Integration to Inclusive Schooling: Current Situation and New Teacher Training Needs. An Unpublished Research Report, Université de Caen Basse-Normandie.

Ball, D. L., Sleep, L., Boerst, T., \& Bass, H. (2009). Combining the Development of Practice and the Practice of Development in Teacher Education. Elementary School Journal, 109, 458-474. https://doi.org/10.1086/596996

Bernard, R. M., Abrami, P. C., Lou, Y., Borokhovski, E., Wade, A., Wozney, L., \& Huang, B. (2004). How Does Distance Education Compare with Classroom Instruction? A MetaAnalysis of the Empirical Literature. Review of Educational Research, 74, 379-439. https://doi.org/10.3102\%2F00346543074003379

Cavanaugh, C. S. (2001). The Effectiveness of Interactive Distance Education Technologies in K-12 Learning: A Meta-Analysis. International Journal of Educational Telecommunications, 7, 73-88.

Crankson, S., Agyeman, K. D., \& Narh-Kert, M. (2020). Pre-Service Teachers' Perception of Their Mathematics Classroom Environment in Ghanaian Colleges of Education. American Journal of Educational Research, 8, 739-745.

Cybinski, P., \& Selvanathan, S. (2005). Learning Experience and Learning Effectiveness in Undergraduate Statistics: Modelling Performance in Traditional and Flexible Learning Environments. Decision Sciences Journal of Innovative Education, 3, 251-271. https://doi.org/10.1111/j.1540-4609.2005.00069.x

Deka, T. S., \& McMurry, P. (2006). Student Success in Face-to-Face and Distance Teleclass Environments: Matter of Contact? International Review of Research in Open and Distance Learning, 7, 1-16. https://doi.org/10.19173/irrodl.v7i1.251

Machtmes, K., \& Asher, J. W. (2000). A Meta-Analysis of the Effectiveness of Telecourses in Distance Education. The American Journal of Distance Education, 14, 27-46. https://doi.org/10.1080/08923640009527043

Narh-Kert, M. (2020). Predictive Validity of Entry Level Mathematics on Mathematical Knowledge of Pre-Service Teachers for Teaching Basic School mathematics in Ghana. Texila International Journal of Academic Research, 7, 17-28. https://doi.org/10.21522/TIJAR.2014.07.02.Art003

Narh-Kert, M., \& Ampadu, E. (2020). Assessing Factors Influencing Pre-Service Teachers' Mathematical Knowledge for Teaching (MKT) Mathematics in Ghanaian Basic Schools. Texila International Journal of Academic Research, 7, 46-60. https://doi.org/10.21522/TIJAR.2014.07.01.Art004

Narh-Kert, M., \& Ampadu, E. (2021). Statistical Modelling of the Academic Performance of Pre Service Teachers of Regular and Distance Education in Ghana. Psychology and Education Journal, 58, 1948-1957.

Narh-Kert, M., Agyeman, K. D., \& Crankson, S. (2021). Attitude towards Mathematics: The Case of Pre-Service Mathematics Teachers in Selected Colleges of Education in Ghana. Social Science Learning Education Journal, 6.

https://doi.org/10.15520/sslej.v6i2.2769

Ramage, T. R. (2002). The "No Significant Difference" Phenomenon: A Literature Review. http://spark.parkland.edu/ramage pubs/1/ 
Savolainen, H. (2009). Responding to Diversity and Striving for Excellence: The Case of Finland. PROSPECTS, 39, 281-292. https://doi.org/10.1007/s11125-009-9125-y

Schoenfeld-Tacher, R., McConnell, S., \& Graham, M. (2001). Do No Harm: A Comparison of the Effects of On-Line vs. Traditional Delivery Media on a Science Course. Journal of Science Education and Technology, 10, 257-265.

https://doi.org/10.1023/A:1016690600795

Shachar, M., \& Neumann, Y. (2003). Differences between Traditional and Distance Education. Academic Performance: A Meta-Analytic Approach, 4, 1-20.

https://doi.org/10.19173/irrodl.v4i2.153

Tucker, S. Y. (2000). Assessing the Effectiveness of Distance Education versus Traditional On-Campus Education. Paper Presented at the Annual Meeting of the American Educational Research Association, New Orleans, 24-28 April 2000.

Zhao, Y., Lei, J., Yan, B., \& Tan, S. (2004). What Makes the Difference? A Practical Analysis of Research on the Effectiveness of Distance Education. Teachers College Record, 107, 1836-1884. 